\title{
Cationic zinc (II) dimers and one dimensional coordination polymer from ionic carboxylic acid
}

\author{
PALADUGU SURESH and GANESAN PRABUSANKAR* \\ Department of Chemistry, Indian Institute of Technology Hyderabad, ODF Campus, \\ Yeddumailaram, 502205 India \\ e-mail: prabu@iith.ac.in
}

MS received 28 March 2014; revised 17 May 2014; accepted 22 May 2014

\begin{abstract}
A rare example of chelating two tetra cationic paddle-wheel zinc dimers were synthesized from the reaction between flexible imidazolium carboxylate $\left(\mathbf{L H}_{\mathbf{2}} \mathbf{B} \mathbf{r}_{2}\right)$ and corresponding zinc precursors. A zinc coordination polymer was synthesised by treating in situ generation of $\mathbf{2}$ in the presence of 4,4'-bipyridine. These new molecules, dimers and polymer, were characterized by FT-IR, NMR, UV-vis, fluorescent and single crystal X-ray diffraction techniques. Zinc polymer is the first example of 1D coordination polymer constructed by tetra cationic zinc dimer as a secondary building unit in coordination polymer.
\end{abstract}

Keywords. Imidazolium carboxylate; secondary building units; zinc dimers; 4,4'-bipyridine; zinc coordination polymer.

\section{Introduction}

Construction of functionalized coordination polymers have attracted a lot of attention in recent decades due to their potential applications in the field of gas separation, ${ }^{1}$ gas adsorption, ${ }^{2}$ drug delivery, ${ }^{3}$ sensors, ${ }^{4}$ nonlinear optics, ${ }^{5}$ magnetic materials, ${ }^{6}$ conducting application, ${ }^{7}$ and catalysis. ${ }^{8}$ An important tool to design and synthesize coordination polymers is secondary building unit (SBU). To design and synthesize coordination polymers, one of the most important tool is secondary building unit (SBU). Till now, more than 150 different secondary building units have been reported for coordination polymers. ${ }^{9}$ In which, square shaped paddle-wheel is one of the most important building blocks in coordination polymers, where two metal atoms are bridged by four carboxylates and mostly metal atoms are in apical position. The square shaped paddle-wheel building blocks are commonly known as $\mathrm{Zn}, \mathrm{Cu}, \mathrm{Rh}, \mathrm{Ru}, \mathrm{Mo}, \mathrm{Ni}, \mathrm{Co}, \mathrm{Re}, \mathrm{Cr}, \mathrm{Mn}, \mathrm{W}, \mathrm{Pt}$, $\mathrm{Mg}, \mathrm{Al}$ and In. ${ }^{9}$ Some well-known examples are MOF5 for $\mathrm{Zn}$ square shaped paddle-wheel and HKUST for $\mathrm{Cu}$ square shaped paddle-wheel. ${ }^{10}$ Recently, Kitagawa et al. have reported the isostructural $\mathrm{Ru}$ and $\mathrm{Rh}$ 1D coordination polymers from corresponding paddle wheel dimers of $\left[\mathrm{M}_{2}\left(4-\mathrm{Cl}-2-\mathrm{OMePhCO}_{2}\right)_{4}(\mathrm{THF})_{2}\right]$ $(\mathrm{M}=\mathrm{Ru}, \mathrm{Rh})$ using phenazine (phz) as a linker for the selective NO molecules tapping, which is considered as

*For correspondence

This paper is dedicated to Professor S S Krishnamurthy. one of the most important synthetic protocols to construct the functional materials. ${ }^{11}$ However, the chelating carboxylate zinc paddle-wheel dimers are rare, ${ }^{12}$ in particular the coordination polymers with chelating zinc carboxylate paddle wheel building block are not known. Thus, we report two new tetra cationic zinc dimers (1 and 2) and cationic zinc 1D coordination polymer (3). The structural and optical properties of $\mathbf{1 - 3}$ (scheme 1) were studied.

\section{Experimental}

\subsection{General considerations}

The solvents were purchased from commercial sources and purified according to standard procedures. ${ }^{13}$ Unless otherwise stated, the chemicals were purchased from commercial sources. $\mathbf{L H}_{\mathbf{2}} \mathbf{B} \mathbf{r}_{\mathbf{2}}$ was prepared as reported. ${ }^{14}$ FT-IR measurement (neat) was carried out on a Bruker Alpha-P Fourier transform spectrometer. NMR spectra were recorded on Bruker Ultrashield400 spectrometers at $25^{\circ} \mathrm{C}$, unless otherwise stated. Chemical shifts are given relative to TMS and were referenced to the solvent resonances as internal standards. The UV-vis spectra were measured on a T90+ UV-visible spectrophotometer. The fluorescent emission spectra were measured on a Horiba Scientific fluorescence spectrophotometer. The crystal structures of 13 were measured on an Oxford Xcalibur 2 diffractometer. Data were collected at $150 \mathrm{~K}$. Using Olex $2,{ }^{15}$ the 


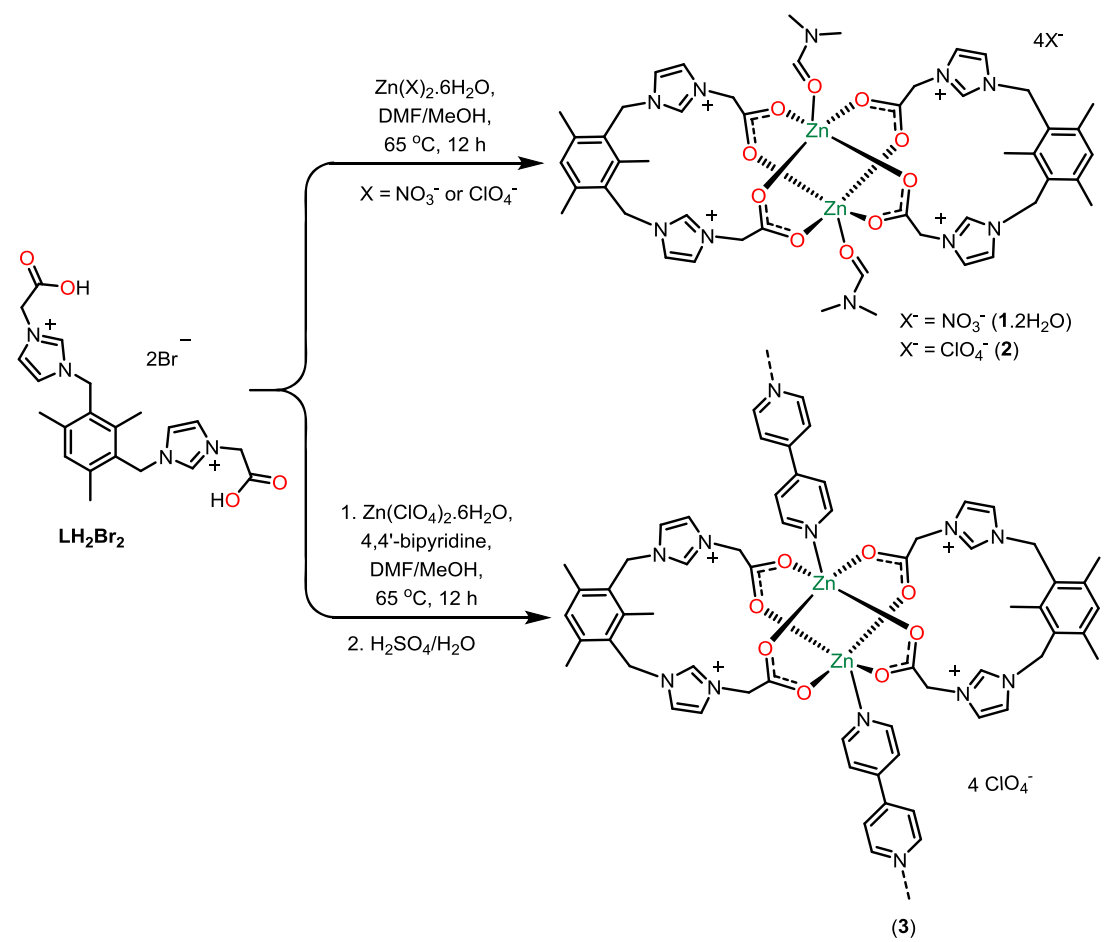

Scheme 1. Synthesis of 1-3.

structures were solved with the ShelXS ${ }^{16}$ structure solution program using Direct Methods and refined with the olex2.refine refinement package using Gauss-Newton minimization. In 1, hydrogen atoms for water molecule were not included during the final refinement. Some of the perchlorate anions in $\mathbf{2}$ and $\mathbf{3}$ are disordered. Therefore, the complete refinement was not possible for $\mathbf{2}$ and 3 .

\subsection{Synthesis of $\mathbf{1}$}

$\mathbf{L H}_{2} \mathbf{B r}_{2}(0.1 \mathrm{~g}, 0.179 \mathrm{mmol})$ and $\mathrm{Zn}\left(\mathrm{NO}_{3}\right)_{2} \cdot 6 \mathrm{H}_{2} \mathrm{O}$ $(0.054 \mathrm{~g}, 0.181 \mathrm{mmol})$ were taken into schlenk tube and added 1:1 DMF and $\mathrm{MeOH}(2 \mathrm{~mL})$. The reaction mixture was heated at $65^{\circ} \mathrm{C}$ under stirring condition for $12 \mathrm{~h}$. After ten days, colourless crystals were formed and washed with $\mathrm{MeOH}$ then dried under vacuum. Yield: $24 \%$ (based on $\left.\mathrm{Zn}\left(\mathrm{NO}_{3}\right)_{2} \cdot 6 \mathrm{H}_{2} \mathrm{O}\right)$. Anal. Calcd. (\%) for $\mathrm{C}_{48} \mathrm{H}_{66} \mathrm{~N}_{14} \mathrm{O}_{24} \mathrm{Zn}_{2}$ (1353.87): C, 42.58; $\mathrm{H}, 4.91$; N, 14.48; found: C, 42.3; H, 5.1; N, 14.3. ${ }^{1} \mathrm{H}$ NMR (400 MHz, $\left.\mathrm{D}_{2} \mathrm{O}\right): \delta 8.47(\mathrm{~s}, 2 \mathrm{H}, \mathrm{Im} H), 7.92$ (s, $1 \mathrm{H}, \mathrm{DMF} \mathrm{CH}) 7.44$ and 7.35 (s, $2 \times 2 \mathrm{H}, 2 \times \operatorname{Im} H$ ), $7.25\left(\mathrm{~s}, 1 \mathrm{H}\right.$, Ar $H$ ), 5.51 (s, 4H, Mes $\left.\mathrm{CH}_{2} \mathrm{~N}\right), 4.73$ (s, 4H, $\mathrm{CH}_{2}$ ), 3.00 (s, 3H, DMF $\left.\mathrm{CH}_{3}\right), 2.84$ (s, 3H, DMF $\mathrm{CH}_{3}$ ), 2.34 (s, 6H, Mes $\left.\mathrm{CH}_{3}\right), 2.21$ (s, 3H, Mes $\left.\mathrm{CH}_{3}\right)$ ppm. ${ }^{13} \mathrm{C}$ NMR $\left(100 \mathrm{MHz}, \mathrm{D}_{2} \mathrm{O}\right): \delta 172.13$ (DMF $C=\mathrm{O}), 164.94(C=\mathrm{O}), 140.85(\operatorname{Ar} C), 139.18(\operatorname{Ar} C)$, 135.87 (Im $C$ ), 131.36 (Ar $C$ ), $127.70(\operatorname{Ar} C), 123.78$ $(\operatorname{Im} C), 121.57(\operatorname{Im} C), 52.02\left(\mathrm{DMF} C \mathrm{H}_{3}\right), 47.70$
$\left(\mathrm{Mes} \mathrm{CH}_{2}\right), 36.89\left(\mathrm{CH}_{2}\right), 31.36\left(\mathrm{DMF} \mathrm{CH}_{3}\right), 18.88$ (Mes $\left.\mathrm{CH}_{3}\right), 14.64$ (Mes $\left.C \mathrm{H}_{3}\right)$ ppm. FT-IR (neat): $\bar{v}=$ 3144 (w), 3107 (w), 3067 (w), 1683 (w), 1648 (s), 1567 (m), 1447 (m), 1409 (m), 1383 (w), 1333 (s), 1234 (w), 1155 (s), 1130 (w), 1103 (w), 1041 (w), 1019 (w), 979 (w) $\mathrm{cm}^{-1}$.

\subsection{Synthesis of 2}

Compound $\mathbf{2}$ was synthesized similar manner as $\mathbf{1}$ using $\mathbf{L H}_{2} \mathbf{B r}_{2}(0.1 \mathrm{~g}, 0.179 \mathrm{mmol})$ and $\mathrm{Zn}\left(\mathrm{ClO}_{4}\right)_{2} \cdot 6 \mathrm{H}_{2} \mathrm{O}$ $(0.067 \mathrm{~g}, 0.180 \mathrm{mmol})$. Colourless crystals were formed after seven days and washed with $\mathrm{MeOH}$ then dried under vacuum. Yield: $63 \%$ (based on $\mathrm{Zn}\left(\mathrm{ClO}_{4}\right)_{2} \cdot 6 \mathrm{H}_{2} \mathrm{O}$ ). Anal. Calcd. (\%) for $\mathrm{C}_{48} \mathrm{H}_{62} \mathrm{~N}_{10} \mathrm{O}_{26} \mathrm{Cl}_{4} \mathrm{Zn}_{2}$ (1467.62): C, 39.28; H, 4.26; N, 9.54; found: C, 39.3; H, 4.2; N, 9.6. ${ }^{1} \mathrm{H}$ NMR $\left(400 \mathrm{MHz}, \mathrm{D}_{2} \mathrm{O}\right): \delta 8.45(\mathrm{~s}, 2 \mathrm{H}, \mathrm{Im} H)$, 7.91 (s, $1 \mathrm{H}$, DMF CH) 7.43 and 7.35 (s, $2 \times 2 \mathrm{H}, 2 \times$ $\operatorname{Im} H$ ), 7.24 (s, $1 \mathrm{H}, \mathrm{Ar} H$ ), $5.50\left(\mathrm{~s}, 4 \mathrm{H}, \mathrm{Mes} \mathrm{CH}_{2} \mathrm{~N}\right)$, 4.73 (s, 4H, $\mathrm{CH}_{2}$ ), 2.99 (s, 3H, DMF $\mathrm{CH}_{3}$ ), 2.84 (s, 3H, DMF CH $H_{3}$ ), 2.33 (s, 6H, Mes $\mathrm{CH}_{3}$ ), 2.21 (s, $3 \mathrm{H}$, Mes $\left.\mathrm{CH}_{3}\right)$ ppm. ${ }^{13} \mathrm{C}$ NMR $\left(100 \mathrm{MHz}, \mathrm{D}_{2} \mathrm{O}\right): \delta$ $172.16(\mathrm{DMF} C=\mathrm{O}), 164.94(C=\mathrm{O}), 140.84(\operatorname{Ar} C)$, 139.19 (Ar $C$ ), 135.85 ( $\operatorname{Im} C$ ), 131.38 (Ar $C$ ), 127.70 $(\operatorname{Ar} C), 123.80(\operatorname{Im} C), 121.60(\operatorname{Im} C), 52.02$ (DMF $\left.\mathrm{CH}_{3}\right), 47.72\left(\mathrm{Mes} \mathrm{CH}_{2}\right), 36.90\left(\mathrm{CH}_{2}\right), 31.37$ (DMF $\mathrm{CH}_{3}$ ), $18.91\left(\mathrm{Mes} \mathrm{CH}_{3}\right), 14.67\left(\mathrm{Mes} \mathrm{CH}_{3}\right)$ ppm. FT-IR (neat): $\bar{v}=3147(\mathrm{w}), 3120(\mathrm{w}), 1691(\mathrm{~m}), 1647(\mathrm{~s})$, 
1571(m), 1448 (m), 1409 (s), $1382(\mathrm{~m}), 1336(\mathrm{w}), 1317$ (m), $1155(\mathrm{~m}), 1068(\mathrm{~s}), 977(\mathrm{w}), 936(\mathrm{w}) \mathrm{cm}^{-1}$.

\subsection{Synthesis of 3}

$\mathbf{L H}_{\mathbf{2}} \mathbf{B r}_{2} \quad(0.1 \quad \mathrm{~g}, \quad 0.179 \mathrm{mmol}), \quad$ 4,4'-bipyridine $(0.028 \mathrm{~g}, 0.179 \mathrm{mmol})$ and $\mathrm{Zn}\left(\mathrm{ClO}_{4}\right)_{2} \cdot 6 \mathrm{H}_{2} \mathrm{O}(0.067 \mathrm{~g}$, $0.180 \mathrm{mmol}$ ) were taken into schlenk tube and added 1:1 DMF and $\mathrm{MeOH}(2 \mathrm{~mL})$. The reaction mixture was heated at $65^{\circ} \mathrm{C}$ under stirring condition for $12 \mathrm{~h}$ and resultant solid was dissolved in $1: 2 \mathrm{H}_{2} \mathrm{O}$ and $\mathrm{H}_{2} \mathrm{SO}_{4}(2$ $\mathrm{mL}$ ). After one week, colourless crystals were formed and washed with $\mathrm{MeOH}$ then dried under high vacuum. Yield: $42 \%$ (based on $\mathrm{Zn}\left(\mathrm{ClO}_{4}\right)_{2} \cdot 6 \mathrm{H}_{2} \mathrm{O}$ ). Anal. Calcd. (\%) for $\mathrm{C}_{52} \mathrm{H}_{56} \mathrm{Cl}_{4} \mathrm{~N}_{10} \mathrm{O}_{24} \mathrm{Zn}_{2}$ (1477.63): C, 42.27; $\mathrm{H}$, 3.82; N, 9.48; found: C, 42.1; H, 3.8; N, 9.4. FT-IR (neat): $\bar{v}=3460(\mathrm{br}), 3087(\mathrm{~m}), 3061(\mathrm{w}), 2995(\mathrm{w})$, 2523 (br), 2347 (w), 2194 (w), 2164 (w), 2123 (w), 2020 (w), 1998 (w), 1952 (w), 1935 (w), 1627 (s), 1485 (s), $1370(\mathrm{~m}), 1239(\mathrm{~m}), 1205(\mathrm{w}), 1109(\mathrm{~m}), 1064(\mathrm{w})$, 1041(m), $983(\mathrm{~m}) \mathrm{cm}^{-1}$.

\section{Results and Discussion}

\subsection{Synthesis and characterization of $\mathbf{1}$ and $\mathbf{2}$}

The zinc dimers $\mathbf{1}$ and $\mathbf{2}$ were synthesized from corresponding zinc metal salts and $\mathbf{L H}_{\mathbf{2}} \mathbf{B} \mathbf{r}_{\mathbf{2}}$ in $\mathrm{DMF} / \mathrm{MeOH}$ at $65^{\circ} \mathrm{C}$ (scheme 1). Compounds $\mathbf{1}$ and $\mathbf{2}$ were formed as colourless crystals and insoluble in almost all organic solvents. Compounds $\mathbf{1}$ and $\mathbf{2}$ were characterized by FTIR, multinuclear $\left({ }^{1} \mathrm{H}\right.$ and $\left.{ }^{13} \mathrm{C}\right) \mathrm{NMR}, \mathrm{UV}$-vis and fluorescent spectroscopy. In FT-IR, 1 displayed the coordinated COO asymmetric stretching frequency at 1648 $\mathrm{cm}^{-1}$ and COO symmetric stretching frequency at 1409 $\mathrm{cm}^{-1}$. In FT-IR, the presence of non-coordinating $\mathrm{NO}_{3}^{-}$ ions in $\mathbf{1}$ was confirmed through stretching frequency at $1333 \mathrm{~cm}^{-1}$. Similarly the presence of $\mathrm{ClO}_{4}^{-}$ions in 2 was supported by FT-IR stretching frequency of 1068 $\mathrm{cm}^{-1}$. The bridging COO group was evidenced by FTIR stretching frequency at 1647 and $1409 \mathrm{~cm}^{-1}$. In ${ }^{1} \mathrm{H}$ $\mathrm{NMR}$, the $\mathrm{N}-\mathrm{CH}-\mathrm{N}$ proton of $\mathbf{1}$ and $\mathbf{2}$ are slightly upfield ( $\delta 8.47 \mathrm{ppm}$ for $\mathbf{1}$ and $8.45 \mathrm{ppm}$ for 2 ) shifted compared to that of $\mathbf{L H}_{2} \mathbf{B r}_{2}(\delta 8.59 \mathrm{ppm})$. The ${ }^{13} \mathrm{C}$ NMR chemical shift value of $\mathrm{C}=\mathrm{O}$ for $\mathbf{1}$ and $\mathbf{2}$ are slightly upfield ( $\delta 164.9 \mathrm{ppm}$ for $\mathbf{1}$ and $\mathbf{2}$ ) shifted compared to that of $\mathbf{L H}_{\mathbf{2}} \mathbf{B} \mathbf{r}_{\mathbf{2}}(\delta 169.9 \mathrm{ppm})$. In compounds $\mathbf{1}$ and $\mathbf{2}$, the presence of two coordinated DMF molecules are confirmed by ${ }^{1} \mathrm{H}$ NMR and ${ }^{13} \mathrm{C}$ NMR.

As shown in figure 1, the solution state and solid state UV-vis absorption spectra are not comparable. The UVvisible absorption spectra of $\mathbf{1}$ and $\mathbf{2}$ were measured in water at room temperature, and displayed the $\lambda_{\max }$ at
$203 \mathrm{~nm}$. The $\lambda_{\max }$ of $\mathbf{1}$ and $\mathbf{2}$ are almost comparable with $\mathbf{L H}_{2} \mathbf{B r}_{2}\left(\lambda_{\max }=202 \mathrm{~nm}\right)$ and this is mainly due to $\pi$ to $\pi^{*}$ transitions of ligand (figure 1a). The solid UV-vis absorption spectrum of $\mathbf{1}$ showed the almost comparable absorption wavelength with $\mathbf{L H}_{2} \mathbf{B r}_{\mathbf{2}}$ at 216, 224 and $271 \mathrm{~nm}$ except $305 \mathrm{~nm}$. Similarly, the solid UV-vis absorption spectrum of $\mathbf{2}$ showed the comparable absorption wavelength with $\mathbf{L H}_{\mathbf{2}} \mathbf{B} \mathbf{r}_{\mathbf{2}}$ at 239 and $274 \mathrm{~nm}$ (figure 1b). The fluorescent emission spectra of $\mathbf{1}$ and $\mathbf{2}$ were measured in water at excitation wavelength of $370 \mathrm{~nm}$. A typical two sets of emission wavelengths $(401 \mathrm{~nm}, 424 \mathrm{~nm}$ for 1 and $400 \mathrm{~nm}, 424 \mathrm{~nm}$ for 2) were observed with strong intensity compared to $\mathbf{L H}_{\mathbf{2}} \mathbf{B r}_{2}$ (figure 1c). In addition, molecule $\mathbf{2}$ showed an additional emission at $445 \mathrm{~nm}$ with weak intensity. In solid fluorescent emission spectra, $\mathbf{1}$ and $\mathbf{2}$ showed the corresponding emission wavelengths at 439 and 440 $\mathrm{nm}$. The fluorescent intensity of $\mathbf{L H}_{\mathbf{2}} \mathbf{B} \mathbf{r}_{\mathbf{2}}$ is much higher than $\mathbf{1}$ and $\mathbf{2}$ (figure 1d).

\subsection{Single crystal X-ray structure of 1 and $\mathbf{2}$}

Compound 1 crystallized in the triclinic space group $P \bar{\imath}$. Data collection parameters are listed in table 1 . The selected bond lengths and bond angles are presented in table 2. The molecular structure of $\mathbf{1}$ is depicted in figure 2. Molecule $\mathbf{1}$ is the first tetracationic zinc dimer with a 'paddle-wheel' structure (figure 3a). Asymmetric unit of $\mathbf{1}$ contains one zinc atom, two half part of $\mathbf{L}$, one coordinated molecule of DMF, one lattice $\mathrm{H}_{2} \mathrm{O}$ and two $\mathrm{NO}_{3}^{-}$anions.

The geometry of zinc(II) is a square pyramidal (figure $3 \mathrm{~b}$ ). The coordination environment around each zinc is fulfilled by four carboxylate moieties of two $\mathbf{L H}_{2} \mathbf{B r}_{2}$ and oxygen atoms of DMF. In each zinc centre, the four carboxylate oxygen atoms are arranged nearly in the basal plane while the oxygen atoms of DMF and a $\mathrm{Zn}$ (II) centre are in the apical position (figure $3 \mathrm{a}$ and $\mathrm{b}$ ). The core structure of $\mathbf{1}$ is comparable with that of $\left[\mathrm{C}_{42} \mathrm{H}_{38} \mathrm{~N}_{6} \mathrm{O}_{10} \mathrm{~S}_{6} \mathrm{Zn}_{2}\right] .{ }^{12 \mathrm{a}}$ The $\mathrm{Zn}$ and $\mathrm{Zn}$ separation distance is 2.969(7) $\AA$, which is slightly longer than that of $\left[\mathrm{C}_{42} \mathrm{H}_{38} \mathrm{~N}_{6} \mathrm{O}_{10} \mathrm{~S}_{6} \mathrm{Zn}_{2}\right]$ $(2.943(5) \AA) .{ }^{12 \mathrm{a}}$. The $\mathrm{Zn}(1)-\mathrm{O}_{\mathrm{COO}}$ bond lengths are in the range of $2.025(2)$ to $2.067(2) \AA$. Notably, the $\mathrm{Zn}(1)-\mathrm{O}(5)_{\mathrm{DMF}}$ bond length $(1.969(2) \AA)$ is shorter than that of $\mathrm{Zn}(1)-\mathrm{O}_{\mathrm{COO}}$. The $\mathrm{O}_{\mathrm{COO}}-\mathrm{Zn}(1)-\mathrm{O}_{\mathrm{COO}}$ angle falls in the range of $86.66(9)^{\circ}$ to $159.46(9)^{\circ}$ and $\mathrm{O}_{\mathrm{DMF}^{-}}$ $\mathrm{Zn}(1)-\mathrm{O}_{\mathrm{COO}}$ angle falls in the range of $95.03(9)^{\circ}$ to $105.68(9)^{\circ}$. Therefore, the overall structural features of $\mathbf{1}$ are slightly different from the known similar class of neutral zinc carboxylate dimer.

Compound 2 crystallized in the triclinic space group $P \bar{l}$. Data collection parameters are listed in table 1 . The 

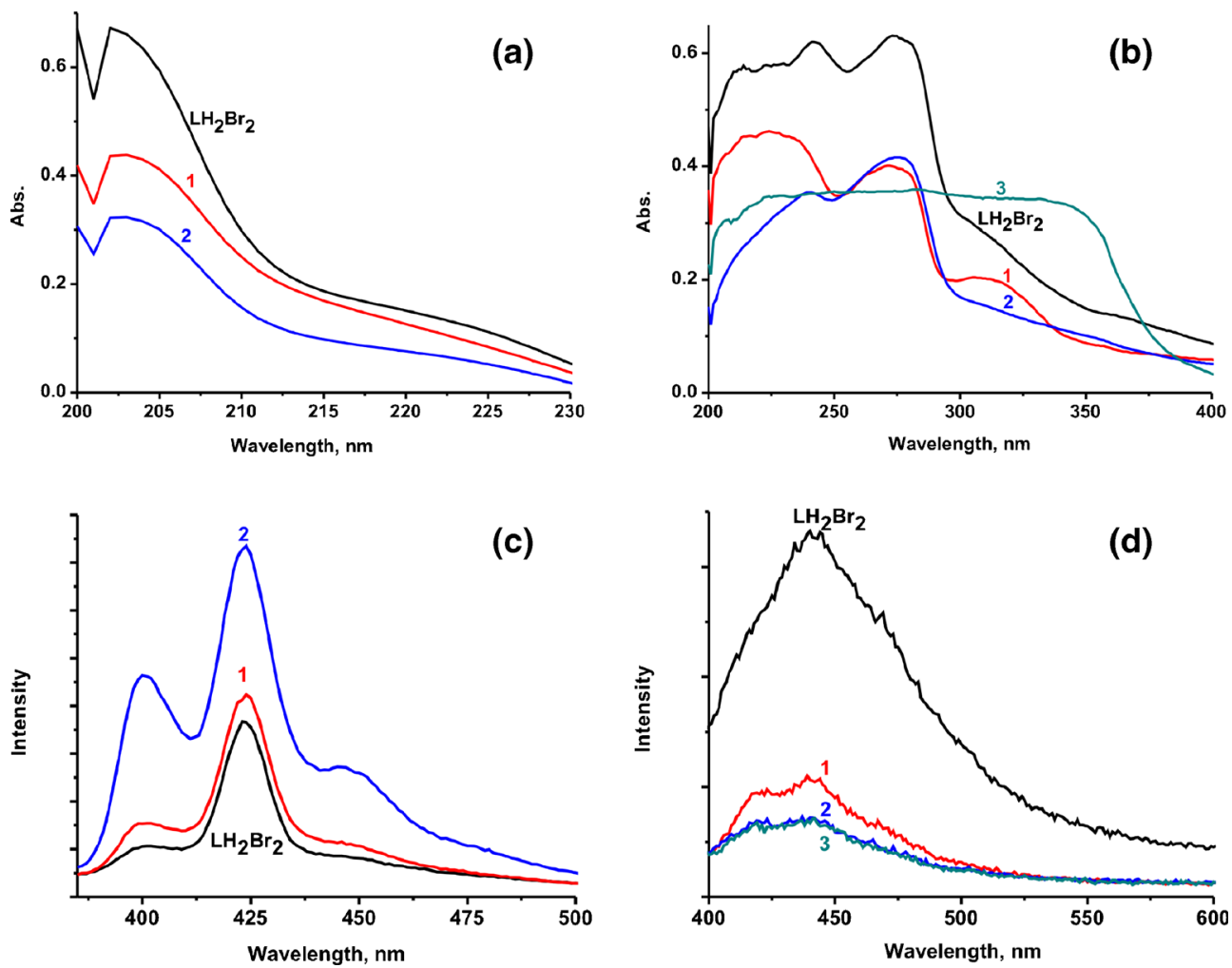

Figure 1. (a) The UV-vis absorption spectra of $\mathbf{L H}_{\mathbf{2}} \mathbf{B} \mathbf{r}_{2}, \mathbf{1}$ and $\mathbf{2}$ in water at $\mathrm{rt}\left(1.6 \times 10^{-6}\right.$ M). (b) The solid-state UV-vis absorption of 1-3 and $\mathbf{L} \mathbf{H}_{2} \mathbf{B r}_{2}$ at rt. (c) The fluorescent spectra of $\mathbf{L H}_{2} \mathbf{B r}_{2}, \mathbf{1}$ and $\mathbf{2}$ in water at rt with excitation wavelength of $370 \mathrm{~nm}\left(1.6 \times 10^{-6} \mathrm{M}\right)$. (d) The solid-state fluorescent spectra of 1-3 and $\mathbf{L H}_{2} \mathbf{B r}_{2}$.

Table 1. Structural parameters of 1-3.

\begin{tabular}{|c|c|c|c|}
\hline Parameters & 1 & 2 & 3 \\
\hline Empirical formula & $\mathrm{C}_{48} \mathrm{H}_{62} \mathrm{~N}_{14} \mathrm{O}_{24} \mathrm{Zn}_{2}$ & $\mathrm{C}_{48} \mathrm{H}_{62} \mathrm{Cl}_{4} \mathrm{~N}_{10} \mathrm{O}_{26} \mathrm{Zn}_{2}$ & $\mathrm{C}_{52} \mathrm{H}_{56} \mathrm{Cl}_{5} \mathrm{~N}_{10} \mathrm{O}_{28} \mathrm{Zn}_{2}$ \\
\hline Formula weight & 1349.90 & 1467.68 & 1577.13 \\
\hline Temperature (K) & 150 & 150 & 150 \\
\hline Crystal system & triclinic & triclinic & triclinic \\
\hline Space group & $P \bar{l}$ & $P \bar{l}$ & $P \bar{l}$ \\
\hline$a / \AA$ & $9.8562(8)$ & $9.8818(12)$ & $11.3785(6)$ \\
\hline$b / \AA$ & $10.9897(9)$ & $10.8661(11)$ & $11.7799(6)$ \\
\hline$c / \AA ̊$ & $14.8662(6)$ & $15.3988(19)$ & $13.7768(5)$ \\
\hline$\alpha /^{\circ}$ & $93.136(5)$ & $90.332(9)$ & $71.415(5)$ \\
\hline$\beta /^{\circ}$ & $92.944(5)$ & $90.724(10)$ & $66.956(5)$ \\
\hline$\gamma /{ }^{\circ}$ & $113.362(7)$ & $111.427(11)$ & $78.817(4)$ \\
\hline Volume $\left(\AA^{3}\right)$ & $1471.3(2)$ & $1539.0(3)$ & $1605.57(15)$ \\
\hline$Z$ & 1 & 1 & 1 \\
\hline$\rho_{\text {calc }} / \mathrm{mg} \mathrm{mm}^{-3}$ & 1.5234 & 1.5835 & 1.6310 \\
\hline Absorption coefficient $\left(\mathrm{mm}^{-1}\right)$ & 1.812 & 3.349 & 3.658 \\
\hline$F(000)$ & 699.4 & 756.9 & 808.4 \\
\hline Data collected & 10579 & 6144 & 11867 \\
\hline Unique data & 5521 & 4474 & 6024 \\
\hline$R_{\text {int }}$ & 0.0249 & 0.0272 & 0.0327 \\
\hline GOF on $F^{2}$ & 1.049 & 1.048 & 1.794 \\
\hline$R_{1}(I>2 s(I))$ & 0.0549 & 0.0840 & 0.1347 \\
\hline $\mathrm{w} R_{2}(\mathrm{I}>2 s(I))$ & 0.0159 & 0.2343 & 0.4133 \\
\hline$R_{1}$ values (all data) & 0.0583 & 0.0867 & 0.1483 \\
\hline $\mathrm{w} R_{2}$ values (all data) & 0.1589 & 0.2344 & 0.4133 \\
\hline
\end{tabular}


Table 2. Bond lengths and angles of compounds 1, 2 and $\mathbf{3 .}$

\begin{tabular}{|c|c|c|c|c|}
\hline & {$\left[\mathrm{C}_{42} \mathrm{H}_{38} \mathrm{~N}_{6} \mathrm{O}_{10} \mathrm{~S}_{6} \mathrm{Zn}_{2}\right]^{12 \mathrm{a}}$} & 1 & 2 & 3 \\
\hline & \multicolumn{4}{|c|}{ Bond lengths $(\AA)$} \\
\hline $\mathrm{Zn}$ to $\mathrm{Zn}$ & $2.943(5)$ & $2.969(7)$ & $2.966(12)$ & $2.998(11)$ \\
\hline $\mathrm{Zn}-\mathrm{O}_{\mathrm{DMF}}$ & $1.982(15)$ & $1.969(2)$ & $1.962(4)$ & - \\
\hline $\mathrm{Zn}-\mathrm{O}_{\mathrm{COO}}$ & $2.027(16)-2.044(16)$ & $2.025(2)-2.067(2)$ & 2.034(4)-2.074(4) & $2.030(5)-2.059(5)$ \\
\hline \multirow{2}{*}{$\mathrm{Zn}-\mathrm{N}$} & - & - & - & $2.035(6)$ \\
\hline & \multicolumn{4}{|c|}{ Bond angles $\left({ }^{\circ}\right)$} \\
\hline $\mathrm{O}_{\mathrm{COO}}-\mathrm{Zn}-\mathrm{O}_{\mathrm{COO}}$ & $85.74(7)-159.86(7)$ & 86.66(9)-159.46(9) & $86.53(16)-159.54(16)$ & $87.2(2)-158.6(2)$ \\
\hline $\mathrm{O}_{\mathrm{DMF}}-\mathrm{Zn}-\mathrm{O}_{\mathrm{COO}}$ & $99.34(7)-100.89(7)$ & $95.03(9)-105.68(9)$ & $93.61(16)-106.85(17)$ & - \\
\hline $\mathrm{N}-\mathrm{Zn}-\mathrm{O}_{\mathrm{COO}}$ & - & - & - & $95.9(2)-105.4(2)$ \\
\hline
\end{tabular}

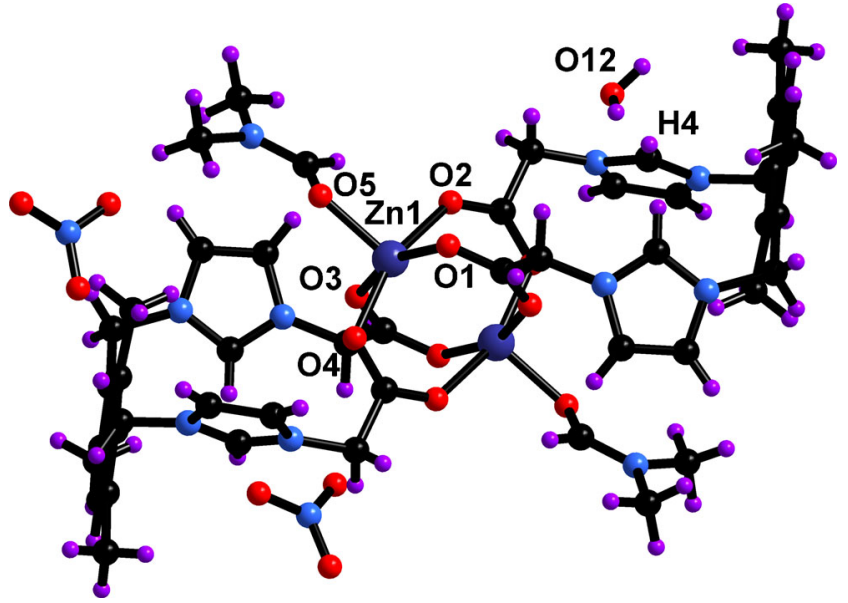

Figure 2. Molecular structure of $\mathbf{1}$.

selected bond lengths and bond angles are presented in table 2. The molecular structure of $\mathbf{2}$ is shown in figure 4 . The single crystal $\mathrm{X}$-ray structure of $\mathbf{2}$ is isostructural with $\mathbf{1}$. Thus, the structure feature of $\mathbf{2}$ has not been discussed in detail. However, the structural parameters of $\mathbf{1}$ and $\mathbf{2}$ are significantly different. These are differing by the counter ion and lattice water molecule. In $\mathbf{2}$, the $\mathrm{Zn}$ and $\mathrm{Zn}$ separation distance $(2.966(12) \AA$ ) is nearly comparable with that of 1 . The $\mathrm{Zn}(1)-\mathrm{O}_{\mathrm{COO}}$ bond lengths are in the range from 2.033(4) to 2.074(4) ^. Notably, the Zn(1)$\mathrm{O}(5)_{\mathrm{DMF}}$ bond length (1.962(4) $\AA$ ) is shorter than that of

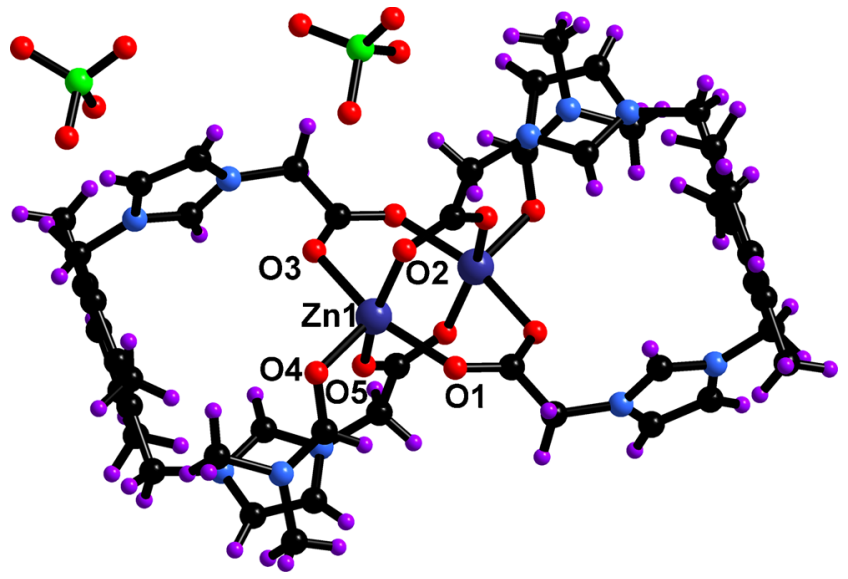

Figure 4. Molecular structure of 2.

$\mathrm{Zn}(1)-\mathrm{O}_{\mathrm{COO}}$. The $\mathrm{O}_{\mathrm{COO}}-\mathrm{Zn}(1)-\mathrm{O}_{\mathrm{COO}}$ angle falls in the range of $86.53(16)$ to $159.54(16)^{\circ}$ and $\mathrm{O}_{\mathrm{DMF}^{-}}$ $\mathrm{Zn}(1)-\mathrm{O}_{\mathrm{COO}}$ angle falls in the range of 93.61(16) to $106.85(16)^{\circ}$.

\subsection{Synthesis and characterization of $\mathbf{3}$}

The zinc polymer 3 was synthesized from the reaction of $\mathrm{Zn}\left(\mathrm{ClO}_{4}\right)_{2} \cdot 6 \mathrm{H}_{2} \mathrm{O}$, 4,4'-bipyridine and $\mathbf{L H}_{2} \mathbf{B} \mathbf{B r}_{2}$ in $1: 1$ of $\mathrm{DMF} / \mathrm{MeOH}$ at $65^{\circ} \mathrm{C}$ for $12 \mathrm{~h}$ (scheme 1 ). The reaction between $\mathrm{Zn}\left(\mathrm{NO}_{3}\right)_{2} \cdot 6 \mathrm{H}_{2} \mathrm{O}, \mathbf{L H}_{2} \mathbf{B r}_{2}$ and 4,4'-bipyridine in $\mathrm{DMF} / \mathrm{MeOH}$ mixture gave white

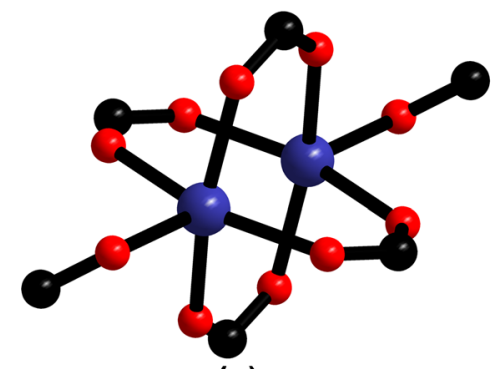

(a)

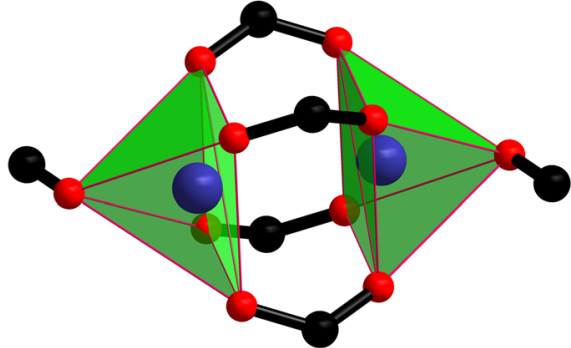

(b)

Figure 3. (a) Core unit of isostructural zinc dimers $\mathbf{1}$ and $\mathbf{2}$ (b) polyhedron view of $\mathbf{1}$ and $\mathbf{2}$. 
precipitate, which was dissolved in concentrated sulfuric acid and water in 1:2 ratio to isolate a known $\left[\mathrm{ZnBr}_{2}(\mu \text {-bpy })\right]_{\infty}$ coordination polymer without L. ${ }^{17}$ Compound $\mathbf{3}$ is insoluble in almost all organic solvents. The compound $\mathbf{3}$ was characterized by FT-IR, UV-vis and fluorescent spectroscopy. In FT-IR, 3 displayed the bridging $\mathrm{COO}$ stretching frequency from 1627 and $1485 \mathrm{~cm}^{-1}$. The band at $1041 \mathrm{~cm}^{-1}$ is associated with $\mathrm{ClO}_{4}^{-}$stretching vibrations. The solid UVvisible absorption spectrum of $\mathbf{3}$ was measured at room temperature, and displayed the absorption wavelength in the range of 209-353 nm as a broad peak (figure 1b). This is mainly due to the $\pi$ to $\pi^{*}$ and $n$ to $\pi^{*}$ transitions of ligand and 4,4'-bipyridine. In solid fluorescent emission spectrum, 3 showed corresponding emission wavelength at $442 \mathrm{~nm}$ and fluorescent intensity of $\mathbf{3}$ is decreases compared to $\mathbf{2}$ and $\mathbf{L H}_{\mathbf{2}} \mathbf{B r}_{\mathbf{2}}$ (figure 1d).

\subsection{Single crystal $X$-ray structure of 3}

Compound $\mathbf{3}$ crystallized in the triclinic space group $P \bar{\imath}$. Data collection parameters are listed in table 1 . The selected bond lengths and bond angles are presented in table 2. The solid state structure of $\mathbf{3}$ is shown in figure 5 . The molecule $\mathbf{3}$ contains $\mathrm{Zn}$ dimer paddle wheel unit of $\mathbf{2}$, two 4,4'-bipyridine and four
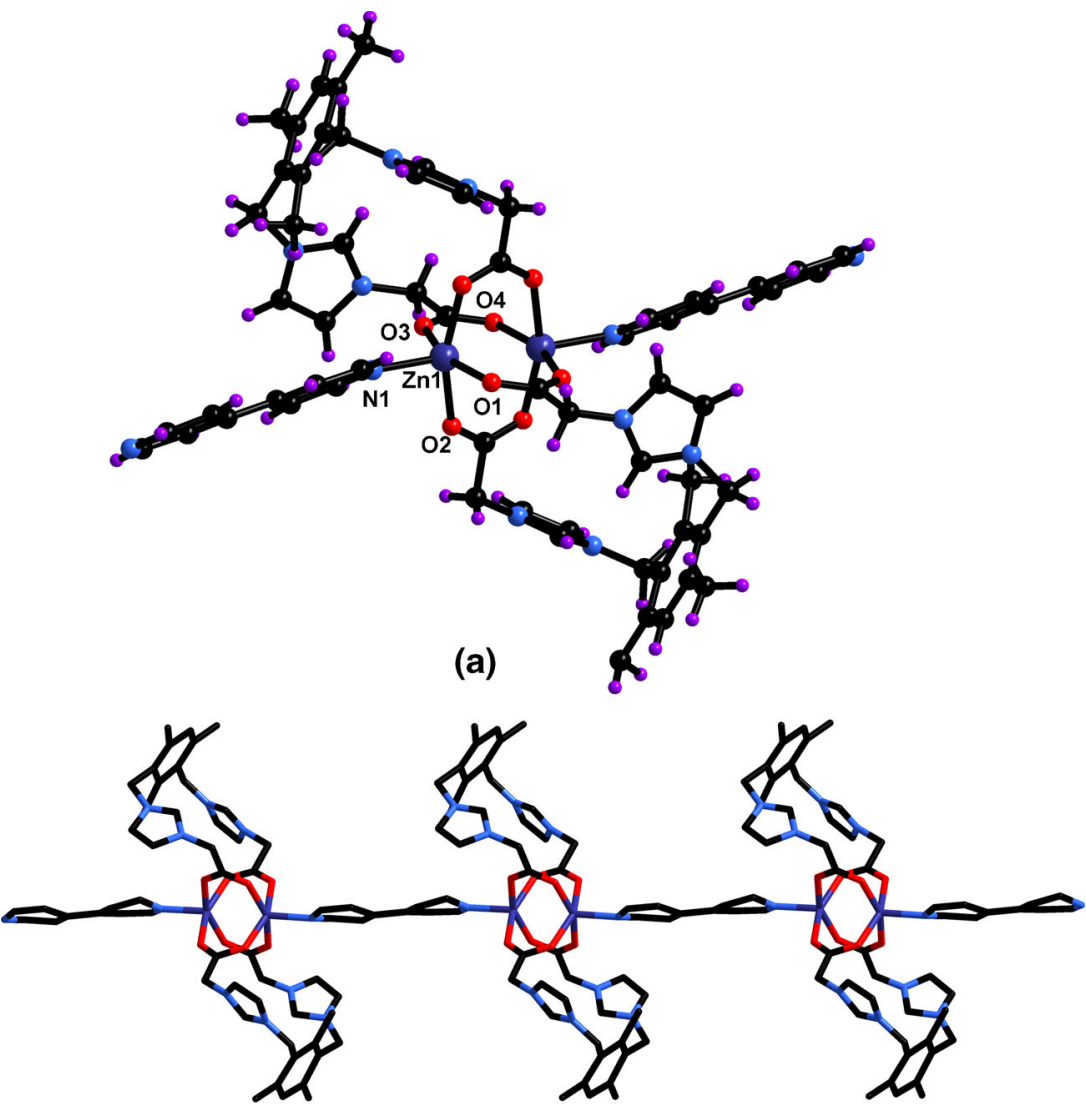

(b)

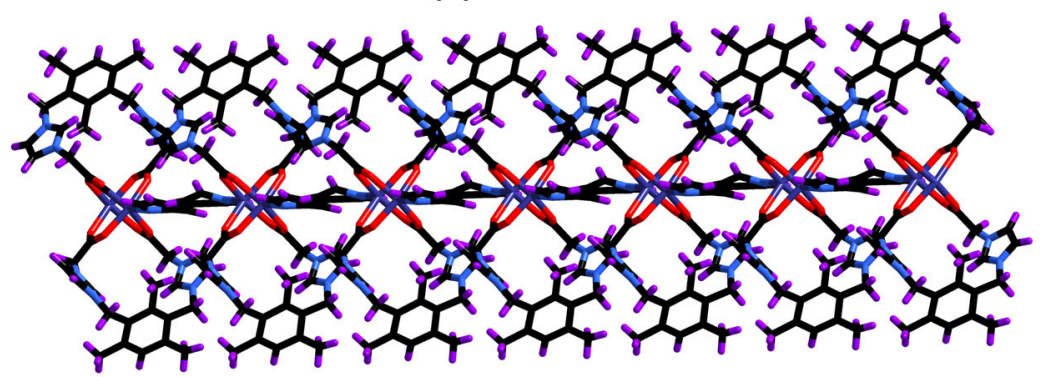

(c)

Figure 5. (a) The coordination environment of $\mathrm{Zn}(\mathrm{II})$ in compound 3 . (b) $1 \mathrm{D}$ chain of $\mathbf{3}$ view along $a$ axis. Hydrogen atoms and $\mathrm{ClO}_{4}^{-}$ions have been omitted for clarity. (c) View of connectivity between square-paddle wheel unit and 4,4'-bipyridine. 
uncoordinated $\mathrm{ClO}_{4}^{-}$anions. The molecule 3 is a $1 \mathrm{D}$ coordination polymer consisting of $[\mathrm{LZn}]_{2}$ core connected by 4,4'-bipyridine. The $\mathrm{Zn}$ and $\mathrm{Zn}$ separation distance is $2.998(11) \AA$, which is slightly longer than that of $\mathbf{1}$ and $\mathbf{2}$. The $\mathrm{Zn}-\mathrm{O}_{\mathrm{COO}}$ bond lengths are in the range of 2.030(5) to 2.059(5) $\AA$. The $\mathrm{Zn}-\mathrm{N}$ bond length is 2.035(6) $\AA$. The $\mathrm{O}_{\mathrm{COO}}-\mathrm{Zn}-\mathrm{O}_{\mathrm{COO}}$ angle falls in the range of $87.2(2)^{\circ}$ to $158.6(2)^{\circ}$. The $\mathrm{N}-\mathrm{Zn}-\mathrm{O}_{\mathrm{CoO}}$ angle falls in the range of $95.9(2)^{\circ}$ to $105.4(2)^{\circ}$.

\section{Conclusion}

In summary, the new tetra cationic zinc dimers $(\mathbf{1}$ and 2) and zinc 1D coordination polymer (3) were synthesized and characterized by FT-IR, NMR, UV-vis, fluorescent and single crystal X-ray diffraction techniques. The zinc dimers $\mathbf{1}$ and $\mathbf{2}$ are rare examples of chelating tetra cationic zinc dimers. Compound $\mathbf{3}$ is the first example of $1 \mathrm{D}$ coordination polymer constructed by zinc dimer core unit connected by 4,4'-bipyridine and the charge is balanced by $\mathrm{ClO}_{4}^{-}$anions. The construction of porous coordination network using tetra cationic zinc dimers is in progress.

\section{Supplementary Information}

CCDC 994145-994147 contains the supplementary crystallographic data for this paper. These data can be obtained free of charge from the Cambridge Crystallographic Data Centre via www.ccdc.cam.ac. uk/data_request/cif sor from the Cambridge Crystallographic Data Centre, 12 Union Road, Cambridge CB2 1EZ, UK; fax: +44 1223336 033; or e-mail: deposit@ccdc.cam.ac.uk

\section{Acknowledgements}

We gratefully acknowledge the DST (SR/FT/CS-94/ 2010) for financial support. P S thanks CSIR for the fellowship.

\section{References}

1. (a) Li J-R, Sculley J and Zhou H-C 2012 Chem. Rev. 112 869; (b) Shigematsu A, Yamada T and Kitagawa H 2012 J. Am. Chem. Soc. 134 13145; (c) Suh M P, Park H J, Prasad T K and Lim D-W 2012 Chem. Rev. 112782

2. (a) Wu H H, Gong Q H, Olson D H and Li J 2012 Chem. Rev. 112 836; (b) Serre C 2012 Angew. Chem. Int. Ed. 51 6048; (c) Bu F, Lin Q P, Zhai G, Wang L, Wu T, Zheng S-T, Bu X H and Feng P Y 2012 Angew. Chem. Int. Ed. $\mathbf{5 1} 8538$

3. (a) Qin J-S, Du D-Y, Li W-L, Zhang J-P, Li S-L, Su Z-M, Wang X-L, Xu Q, Shao K-Z and Lan Y-Q 2012 Chem.
Sci. 3 705; (b) Taylor-Pashow K M L, Rocca J D, Xie Z G, Tran S and Lin W B 2009 J. Am. Chem. Soc. 131 14261

4. (a) Jin X-H, Sun J-K, Cai L-X and Zhang J 2011 Chem. Commun. 47 2667; (b) Liu W S, Jiao T Q, Li Y Z, Liu Q Z, Tan M Y, Wang H and Wang L F 2004 J. Am. Chem. Soc. 126 2280; (c) An J, Shade C M, Chengelis-Czegan D A, Petoud S and Rosi N L 2011 J. Am. Chem. Soc. 1331220

5. (a) Yin Z, Wang Q-X and Zeng M-H 2012 J. Am. Chem. Soc. 134 4857; (b) Zou J-P, Peng Q, Wen Z H, Zeng G-S, Xing Q-J and Guo G-C 2010 Cryst. Growth Des. 10 2613; (c) Wang Y-L, Fu J-H, Wei J-J, Xu X, Li X-F and Liu Q-Y 2012 Cryst. Growth Des. 124663

6. (a) Zheng S-T, Wu T, Irfanoglu B, Zuo F, Feng P Y and Bu X H 2011 Angew. Chem. Int. Ed. 50 8034; (b) Ma L-F, Han M-L, Qin J-H, Wang L-Y and Du M 2012 Inorg. Chem. 51 9431; (c) Xiao J, Liu B-Y, Wei G and Huang X-C 2011 Inorg. Chem. 5011032

7. (a) Shigematsu A, Yamada T and Kitagawa H $2011 \mathrm{~J}$. Am. Chem. Soc. 133 2034; (b) Yamada T, Sadakiyo M and Kitagawa H 2009 J. Am. Chem. Soc. 131 3144; (c) Sahoo S C, Kundu T and Banerjee R 2011 J. Am. Chem. Soc. 133 17950; (d) Kundu T, Sahoo S C and Banerjee R 2012 Chem. Commun. 484998

8. (a) Roberts J M, Fini B M, Sarjeant A A, Farha O K, Hupp J T and Scheidt K A 2012 J. Am. Chem. Soc. 134 3334; (b) Falkowski J M, Wang C, Liu S and Lin W B 2011 Angew. Chem. Int. Ed. 50 8674; (c) Yoon M, Srirambalaji R and Kim K 2012 Chem. Rev. 112 1196; (d) Lee J, Farha O K, Roberts J, Scheidt K A, Nguyen S T and Hupp J T 2009 Chem. Soc. Rev. 38 1450; (e) Jeong K S, Go Y B, Shin S M, Lee S J, Kim J, Yaghi O M and Jeong N 2011 Chem. Sci. 2 877; (f) Ma L Q, Abney C and Lin W B 2009 Chem. Soc. Rev. 38 1248; (g) Yamazaki H, Shouji A, Kajita M and Yagi M 2010 Coord. Chem. Rev. 2542483

9. (a) Tranchemontagne D J, Mendoza-Cortes J L, O'Keeffe M and Yaghi O M 2009 Chem. Soc. Rev. 38 1257; (b) Perry IV J J, Perman J A and Zaworotko M J 2009 Chem. Soc. Rev. 38 1400; (c) Furukawa H, Cordova K E, O'keeffe M and Yaghi O M 2013 Science 3416149

10. Eddaoudi M, Moler D B, Li H, Chen B, Reineke T M, O'Keeffe M and Yaghi O M 2001 Acc. Chem. Res. 34 319

11. Kosaka W, Yamagishi K, Hori A, Sato H, Matsuda R, Kitagawa S, Takata M and Miyasaka H $2013 \mathrm{~J}$. Am. Chem. Soc. 13518469

12. (a) Wang P, Ma J P, Li X Y, Huang R Q and Dong Y B 2009 Acta Crystallogr. Sect. C 65 m78; (b) Karmakar A, Sarma R J and Baruah J B 2006 Inorg. Chem. Commun. 91169

13. Perrin D D and Armarego W L F 1988 In Purification of laboratory chemicals $3^{\text {rd }}$ Ed. (London: Pergamon Press)

14. Suresh P, Radhakrishnan S, Naga Babu C, Sathyanarayana A, Sampath N and Prabusankar G 2013 Dalton Trans. 4210838

15. Dolomanov O V, Bourhis L J, Gildea R J, Howard J A K and Puschmann H 2009 J. Appl. Cryst. 42339

16. SHELXS, Sheldrick G M 2008 Acta Crystallogr. A 64112

17. Hu C and Englert U 2001 CrystEngComm 231 